\title{
Fever prevalence and management among three rural communities in the North West Zone, Somalia
}

\author{
R.M. Youssef,, ${ }^{1,2}$ V.A. Alegana, ${ }^{1}$ J. Amran, ${ }^{3}$ A.M. Noor ${ }^{1,4}$ and R.W. Snow ${ }^{1,4}$
}

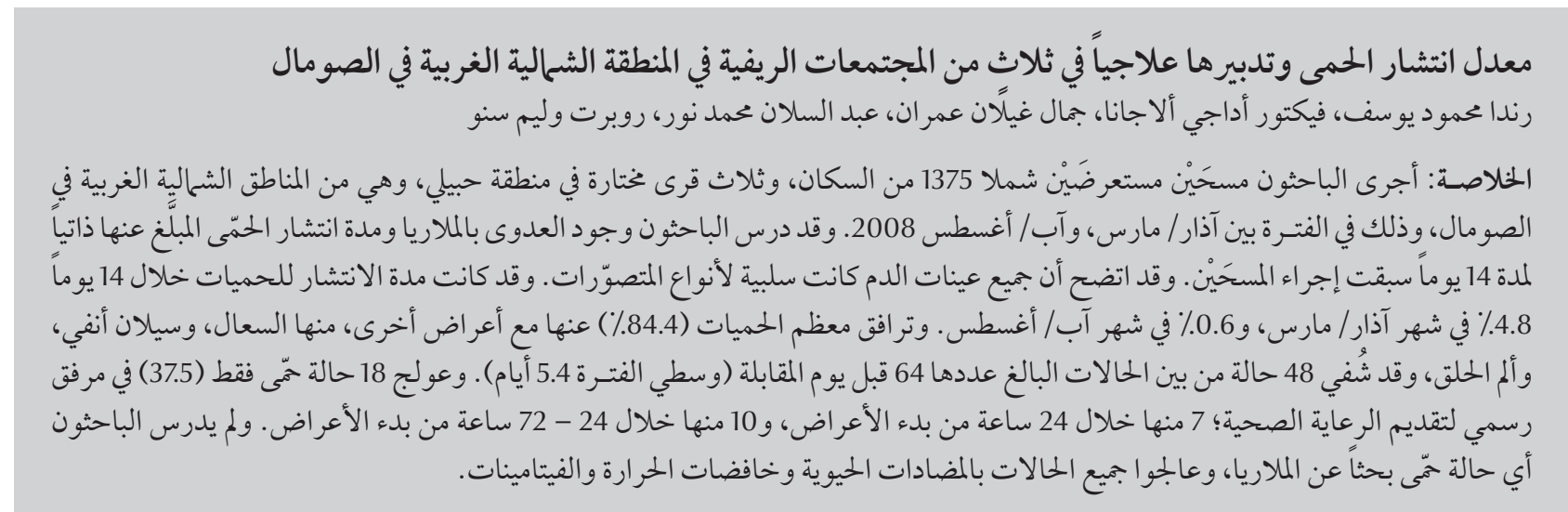

ABSTRACT Between March and August 2008 we undertook 2 cross-sectional surveys among 1375 residents of 3 randomly selected villages in the district of Gebiley in the North-West Zone, Somalia. We investigated for the presence of malaria infection and the period prevalence of self-reported fever 14 days prior to both surveys. All blood samples examined were negative for both species of Plasmodium. The period prevalence of 14-day fevers was $4.8 \%$ in March and $0.6 \%$ in August; the majority of fevers (84.4\%) were associated with other symptoms including cough, running nose and sore throat; $48 / 64$ cases had resolved by the day of interview (mean duration 5.4 days). Only 18 (37.5\%) fever cases were managed at a formal health care facility: 7 within 24 hours and 10 within 24-72 hours of onset. None of the fevers were investigated for malaria; they were treated with antibiotics, antipyretics and vitamins.

\section{Prévalence et prise en charge de la fièvre dans trois communautés rurales du nord-ouest de la Somalie}

RÉSUMÉ Entre mars et août 2008, nous avons réalisé deux études transversales sur 1375 habitants de trois villages sélectionnés au hasard dans le district de Gabiley, au nord-ouest de la Somalie. Nos travaux portaient sur la présence d'une infection paludique ainsi que sur la prévalence périodique des épisodes de fièvre autodéclarés, survenus 14 jours avant les deux études. Tous les prélèvements sanguins analysés se sont révélés négatifs aux deux espèces de Plasmodium. La prévalence périodique des épisodes de fièvre remontant à 14 jours était de $4,8 \%$ en mars, et de $0,6 \%$ en août ; la majorité de ces épisodes $(84,4 \%)$ étaient associés à d'autres symptômes tels qu'une toux, des écoulements nasaux et des maux de gorge. Quarante-huit cas sur 64 étaient résolus le jour de l'entrevue (durée moyenne de l'épisode : 5,4 jours). Seuls 18 cas de fièvre (37,5\%) ont été pris en charge dans un établissement de soins de santé conventionnel : sept dans les 24 heures et dix dans les 24 à 72 heures suivant l'apparition de la fièvre. Le paludisme n'a été recherché chez aucun de ces patients, lesquels ont été traités par antibiotiques, antipyrétiques et vitamines.

'Malaria Public Health and Epidemiology Group, Centre for Geographic Medicine, KEMRI-Wellcome Trust Collaborative Programme, Nairobi, Kenya (Correspondence to R.M. Youssef: randayoussef@link.net).

${ }^{2}$ Department of Community Medicine, Faculty of Medicine, University of Alexandria, Alexandria, Egypt.

${ }^{3}$ Roll Back Malaria, World Health Organization, Hargeisa, Somalia.

${ }^{4}$ Centre for Tropical Medicine, Nuffield Department of Clinical Medicine, University of Oxford Centre for Clinical Vaccinology and Tropical

Medicine, Oxford, United Kingdom.

Received: 08/01/09; accepted: 17/02/09 


\section{Introduction}

The Horn of Africa does not share the same malaria epidemiology as other parts of the African continent. Across Sudan, Djibouti, Ethiopia, Eritrea and Somalia, Plasmodium falciparum and $P$. vivax co-exist. The intensity of malaria transmission is predominantly very low and is maintained almost universally by Anopheles arabiensis. Large areas of semi-arid territory are home to scattered pastoralist and nomadic communities, where conflict and population displacement have damaged the existing sparse routine health services [1].

The prompt and effective treatment of clinical malaria forms the bedrock of all national malaria control strategies irrespective of dominant malaria ecology. Fever is a non-specific symptom of malaria and is used across Africa as the main presenting clinical feature for presumptive malaria therapy. In addition, fever treatment within 48 hours with effective antimalarials is used as the milestone parameter in national sample surveys to measure the success of malaria case-management policies.

In Somalia, the 18 years of conflict and civil war has resulted in a series of humanitarian disasters which left millions deprived of basic health and social services. Attempts are being made to reconstruct the health sector, coordinated by the Somalia Support Secretariat Health Sector Committee. In 2000, the ministries of health of the 3 regional areas of Somalia established a national malaria strategy [2] and through a coalition of development partners secured funding from the Global Fund to fight AIDS, Tuberculosis and Malaria (GFATM) to implement preventative and curative malaria services. The national malaria strategy emphasizes the diagnosis and treatment of malaria within 24 hours of onset of fever with acceptable quality and appropriate dosages of the first line anti-malaria combination therapy (artesunate and sulphadoxine-pyrimethamine) and an expected coverage of $80 \%$ by 2010 .

Very little is known about the basic infection and clinical epidemiology of malaria in Somalia, and even less is known across the North-West Zone of Somalia. In 1946, a malaria reconnaissance mission was undertaken across the then British Somaliland by Wilson [3]. He completed an opportunistic series of village-based parasitological surveys showing an overall $P$. falciparum parasitological index among 600 people surveyed of 11.3\%: P. malariae 1.3\% and P. vivax $0.3 \%$ [3]. Using more recent parasitological data from across Somalia generated as part of food emergency surveys, geospatial models suggest that infection prevalence in most parts of the North-West Zone is < 5\% [4]. Glasgow and MacInnes in 1943 [5] described An. gambiae larval and adult distributions - later confirmed by Maffi in 1958 [6] as An. arabiensis-close to rain-pans and pools and alongside running rivers of the northern foothills.

Nothing is currently known about the extent of febrile illness among the population, the proportion attributed to malaria infection, disease risks or patterns of treatment-seeking behaviour among rural populations in this region of Somalia.

Here we present the results of 2 cross-sectional surveys aimed at describing the risks of fever, malaria infection and treatment-seeking behaviour in 3 rural communities in the district of Gebiley, Somalia North-West Zone.

\section{Methods}

\section{Study area and communities}

TheNorth-WestZone ofSomalia neighbours Djibouti in the north and borders the Red Sea on the east and Ethiopia to the west. Gebiley district is situated $52 \mathrm{~km}$ west of the capital city, Hargeisa, connected by a tarmac road (Figure 1). The majority of the population of this district lives in the town of Gebiley, with the surrounding rural communities connected by small roads. There is no current settlement map or population census of the district. In April 2007, we conducted a rapid survey of settlements and crude population counts across the district to update older census maps. These were used with satellite imagery available on Google Earth [7] to create a sampling frame of 163 communities. We excluded the 4 urban settlements and all rural settlements with estimated populations of less than 100 people ( $n$ $=18$ settlements) to randomly select 3 moderately sized communities for the purposes of the present survey using spatial random sampling techniques in Arcview, version 3.2.

The district has a predominantly arid landscape with small hills and patches of irrigated farmlands. It is an area of acutely seasonal rainfall with an average annual precipitation of $59.9 \mathrm{~mm}$ between 2004 and 2007, with 2 peaks in April and August. The rural communities are predominantly agro-pastoralists of the Isak clan (Somali). They herd goats, sheep, cows and camels, and practise subsistence farming.

Gebiley district has 1 functioning hospital operated by the Ministry of Health and Labour (MoHL) that supports a network of 4 mother and child health centres/out-patient department ( $\mathrm{MCH} / \mathrm{OPD})$ clinics run by qualified nurses and supported by auxiliary nurses and midwives. There are an additional 15 health posts (HPs) staffed by community health workers (Figure 1). Malaria diagnostic services are provided at the district hospital and $\mathrm{MCH} / \mathrm{OPD}$ centres using rapid diagnostic tests. There are several private drug stores in Gebiley town, which sell all types of medication with and without prescription.

The 3 randomly selected communities are shown in Figure 1: Badahabo is $7 \mathrm{~km}$ west of Gebiley town spanning the main road; Xuunshaley is $25 \mathrm{~km}$ west of Gebiley town and $0.1 \mathrm{~km}$ from the main road; and Ceel Bardaale is $42 \mathrm{~km}$ northwest of Gebiley town and $17 \mathrm{~km}$ from 


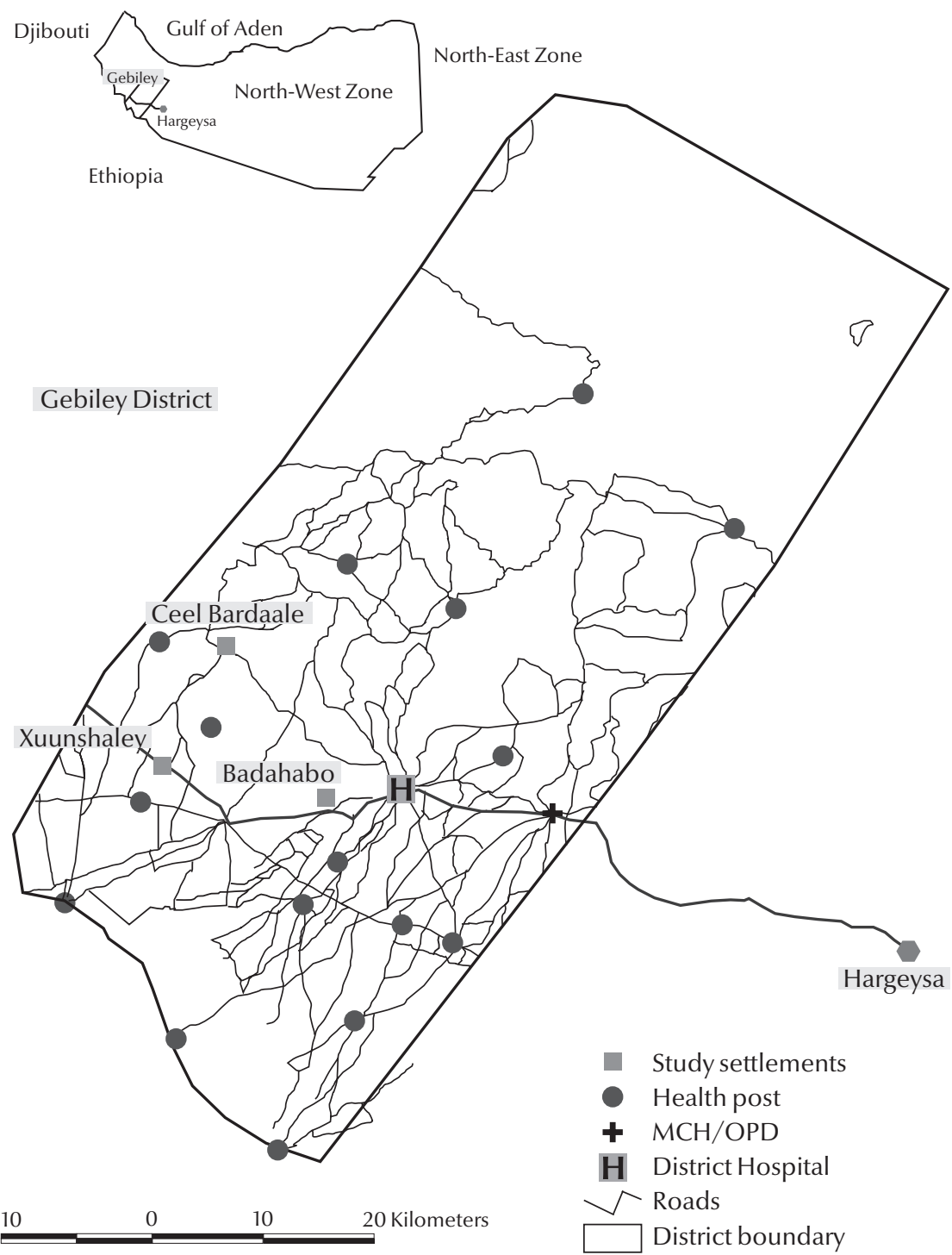

Figure 1 Map of North-West Zone showing Gebiley district (insert); main map shows the position of the 3 selected villages, health services and road networks within Gebiley district

the main road, where households are located along a seasonal river. Only Ceel Bardaale had a functioning HP, established in 1994 and run by the MoHL.

\section{Survey procedures}

Investigators and staff from the MoHL and the World Health Organization (WHO) office in Hargeisa visited each village 2 weeks before the first crosssectional survey in March 2008 to explain the purpose of the survey and discuss participation with the clan elders. Thereafter each homestead was visited and informed consent for participation sought from every head of homestead. consent was obtained in the presence of a literate witness who was not part of the study team. For children below the age of 18 years, informed written consent was obtained from child's guardian. In addition, children aged $12-18$ years were informed about the purpose of taking a blood sample and requested to sign or thumb print an assent form. Copies of the consent and assent forms were given to participants. Participants had the right to refuse participation or withdraw from the study at any stage.

Every consenting resident present in the village during the survey period was questioned on the occurrence of fever in the previous 14 days, its duration and whether the symptom was present on the day of the survey. The investigations were conducted through parents or guardians of all resident children below the age of 12 years. For every reported fever, further details were recorded on when and where the fever was treated and the types of medications and interventions used. A photo-illustrated guide was used to assist recall accuracy on drug types available in the region. Interviews were conducted by trained field workers in Somali dialects spoken by the communities. Clinic records available within the homestead were reviewed and respondents or their mothers/guardians were asked to show medicine packaging if these were still available.

At the end of each interview MoHL technicians took a single finger prick blood sample from each respondent for the preparation of a rapid P. falciparum antigen-specific diagnostic test (Paracheck-Pf, Orchid Biomedical Systems, Goa, India) and a thick and thin blood smear on a glass slide labelled according to homestead and individual unique identifier. All rapid test results were provided to the respondent and used to treat possible positive cases in the field. Thin blood films were fixed at the end of the working day and stained the next morning using 3\% Giemsa solution according to WHO standard procedures [8]. On each slide, 100 high 
power magnification fields were examined by microscopy for P. falciparum and P. vivax and a further 100 fields examined if the first 100 were negative.

The first survey was completed between 29 March and 20 April 2008 and the repeat survey in the same village homesteads was undertaken between 16 August and 18 September 2008, 6 weeks after the onset of the rains reported from Gebiley district for 2008.
All data were entered within 3 weeks of completion of survey procedures using customized data entry screens in EpiInfo, version 6. Data were analysed using SPSS, version 14. Descriptive statistics were used to reveal the point and period prevalence and $95 \%$ confidence interval (CI) of the prevalence of fever by age, sex, wealth, location and action taken to treat this fever. Family wealth was determined based on a number of variables that showed variation from one homestead to another namely possession of radio or television $(0=$ no, 1 $=$ yes), possession of a mobile phone ( $0=$ no, $1=$ yes $)$ and number of heads of sheep $(0=$ none, $1=1-10,2=>10)$, goats $(0=$ none, $1=1-15,2=>15)$, cows $(0=$ none, $1=1-5,2=>5)$, camels $(0=$ none, $1=1-2,2=>2)$ and donkeys $(0=$ none, $1=1-2,2=>2)$. The generated sum of scores was used to classify homesteads into upper, middle or lower wealth tertiles (Table 1).

\begin{tabular}{|c|c|c|c|c|c|c|c|c|}
\hline \multirow[t]{2}{*}{ Variable } & \multicolumn{2}{|c|}{ Xuunshaley } & \multicolumn{2}{|c|}{ Badahabo } & \multicolumn{2}{|c|}{ Ceel Bardaale } & \multicolumn{2}{|c|}{ Total } \\
\hline & No. & $\%$ & No. & $\%$ & No. & $\%$ & No. & $\%$ \\
\hline \multicolumn{9}{|l|}{ March } \\
\hline Homesteads, total & 55 & & 31 & & 130 & & 216 & \\
\hline Surveyed homesteads & 52 & & 31 & & 130 & & 213 & \\
\hline Residents, total & 275 & & 198 & & 806 & & 1279 & \\
\hline Persons refused to participate & 28 & & 1 & & 7 & & 36 & \\
\hline Surveyed residents & 247 & & 185 & & 746 & & 1178 & \\
\hline \multicolumn{9}{|l|}{ August } \\
\hline Homesteads, total & 59 & & 31 & & 124 & & 215 & \\
\hline Surveyed homesteads & 58 & & 30 & & 119 & & 208 & \\
\hline Residents, total & 329 & & 214 & & 820 & & 1363 & \\
\hline Persons refused to participate & 16 & & 15 & & 44 & & 75 & \\
\hline Persons away at time of survey & 42 & & 39 & & 79 & & 160 & \\
\hline Surveyed residents & 271 & & 160 & & 697 & & 1128 & \\
\hline Total homesteads March \& August & 62 & & 32 & & 134 & & 228 & \\
\hline \multicolumn{9}{|l|}{ Wealth asset of homestead ${ }^{a}$} \\
\hline Radio & 21 & 33.9 & 9 & 28.1 & 49 & 36.8 & 79 & 34.8 \\
\hline Mobile telephone & 4 & 6.5 & 1 & 3.1 & 20 & 15.0 & 25 & 11.0 \\
\hline Cows & 60 & 96.8 & 32 & 100.0 & 80 & 60.2 & 172 & 75.8 \\
\hline Goats & 26 & 41.9 & 13 & 40.6 & 123 & 92.5 & 162 & 71.4 \\
\hline Sheep & 40 & 64.5 & 13 & 40.6 & 105 & 78.9 & 158 & 69.6 \\
\hline Donkeys & 29 & 46.8 & 14 & 43.8 & 94 & 70.7 & 137 & 60.4 \\
\hline Camels & 14 & 22.6 & 5 & 15.6 & 45 & 33.8 & 64 & 28.2 \\
\hline \multicolumn{9}{|l|}{ Wealth ranking of homestead ${ }^{a}$} \\
\hline Lower wealth tertile & 28 & 45.2 & 19 & 59.4 & 2 & 18.8 & 72 & 31.7 \\
\hline Middle wealth tertile & 29 & 46.8 & 12 & 37.5 & 70 & 52.6 & 111 & 48.9 \\
\hline Upper wealth tertile & 5 & 8.1 & 1 & 3.1 & 38 & 28.6 & 44 & 19.4 \\
\hline \multicolumn{9}{|l|}{ Net use (homestead, March) } \\
\hline Usually sleep under a net & 0 & 0.0 & 0 & 0.0 & 22 & 3 & 22 & 1.9 \\
\hline Slept under a net last night & 0 & 0.0 & 0 & 0.0 & 11 & 1.5 & 11 & 1.0 \\
\hline \multicolumn{9}{|l|}{ Net use (homestead, August) } \\
\hline Usually sleep under a net & 0 & 0.0 & 0 & 0.0 & 25 & 3.6 & 25 & 2.2 \\
\hline Slept under a net last night & 0 & 0.0 & 0 & 0.0 & 12 & 1.7 & 12 & 1.1 \\
\hline
\end{tabular}

${ }^{a}$ Wealth assets and ranking could not be done for 1 homestead in Ceel Bardaale because of missing data (percentage calculated out of 227 households and 133 households in Ceel Bardaale) 


\section{Ethical approval}

The research protocol was approved by the Research Ethics Review Committee, WHO Headquarters, Geneva (RPC246-EMRO) and the Ethical Committee, MoHL (dated 27 November 2007).

\section{Survey coverage}

In March 2008, a total of 216 homesteads were mapped across the 3 villages and 1279 residents were enumerated (Table 1). Three households with 13 residents refused to participate in addtion to 13 people in the surveyed households. In August 2008, 202 (93.5\%) of the homesteads were still occupied, 12 new homesteads had been established and 1363 residents were enumerated (Table 1). During the August survey 75 residents refused to participate and 160 (11.7\%) could not be traced despite 3 repeat visits over 3 weeks (Table 1). In the 2 surveys, 228 homesteads were visited and 1375 individuals were interviewed: 925 in March and August, 253 in March only and 197 in August only.

\section{Homestead and population characteristics}

The majority of households (92\%) were of the traditional akal/aqal type of rounded sticks and thatch/plastic coverings with a single door entrance with sand or earth floors. The majority of homesteads $(87.8 \%)$ were headed by a man. The majority of homestead heads had never been to school (81.7\%) and $75.1 \%$ were either illiterate or just able to read. Only $2.4 \%$ of homesteads had access to a pit latrine. No homestead had electricity and none of the households in the 3 villages had access to a bicycle or motorcycle. Only 13 households (6.1\%) reported owning a mosquito net in March 2008. Of the 17 nets identified, only 8 were treated with insecticide and the 17 nets were used by 22 people representing $1.9 \%$ population coverage and $1.0 \%$ use during the night prior to the survey. In August, these estimates of usual and previous night use of nets remained similar; $2.2 \%$ and $1.1 \%$ respectively. All nets were located in Ceel Bardaale, the wealthiest and largest village (Table 1).

\section{Prevalence of fever and malaria infection}

The 14-day period prevalence of self-reported fever in March 2008 was $4.8 \%(57 / 1178)$ including 15 people $(1.3 \%)$ who reported fever as present on the day of survey (Table 2). The corresponding value for the August survey was $0.6 \%$ (7/1128) of the population and only 1 person reported fever on the day of the survey (Table 2).

Of the 64 self-reported fevers over the previous 14 days during the combined March and August surveys, 48 (75\%) had resolved after a mean duration of 5.4 (standard deviation 2.67) days and in $16(25.0 \%)$ the fever had started 2-13 days prior to the survey and had not resolved by the day of the survey (Table 2). The majority of fevers $(n=54 ; 84.4 \%)$ reported in the previous 14 days were associated with other symptoms including cough $(n=38)$, headache ( $n$ $=21)$ and running nose $(n=10)$ (Table 3$)$. Seventeen of those with fever and cough were aged under 15 years and 12 were aged $>60$ years. Self reported fever was more prevalent among males, those aged $<5$ years, those $>15$ years and those in the middle wealth tertile.

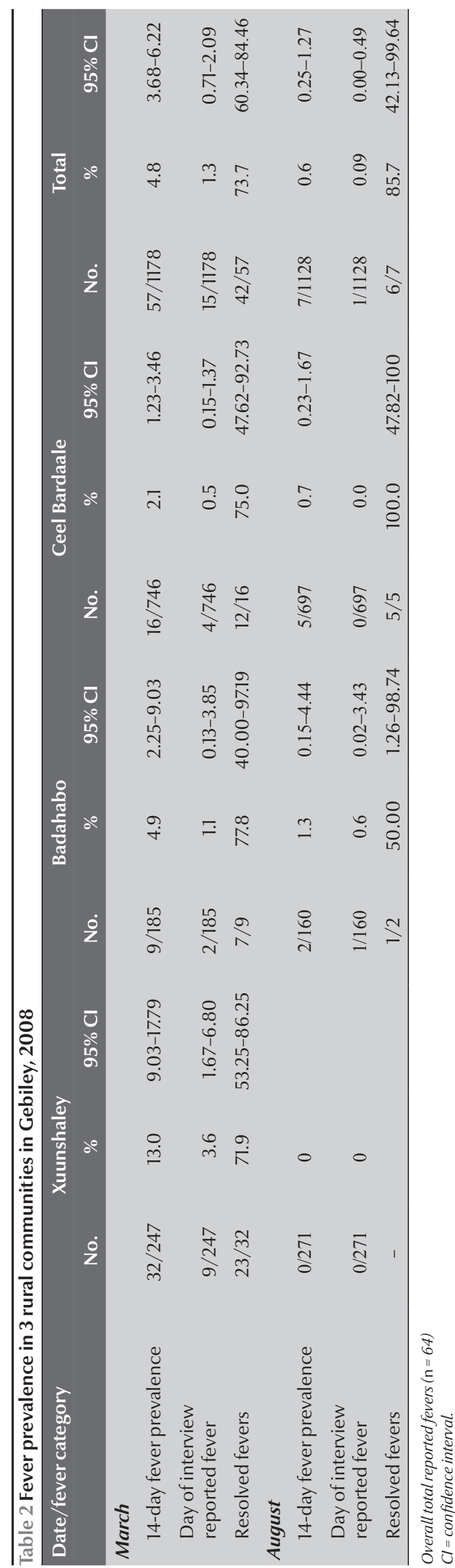




\begin{tabular}{|c|c|c|c|}
\hline Characteristic & No. & $\%$ & $95 \% \mathrm{Cl}$ \\
\hline \multicolumn{4}{|l|}{ Sex } \\
\hline Male $(n=693)$ & 39 & 5.6 & $4.09-7.54$ \\
\hline Female $(n=682)$ & 25 & 3.64 & $2.37-5.33$ \\
\hline \multicolumn{4}{|l|}{ Age } \\
\hline$<5$ years $(n=255)$ & 12 & 4.7 & $2.57-7.86$ \\
\hline $5-14$ years $(n=409)$ & 18 & 4.4 & $2.71-6.74$ \\
\hline $15+$ years $(n=711)$ & 34 & 4.8 & $3.39-6.54$ \\
\hline \multicolumn{4}{|l|}{ Wealth ranking } \\
\hline Lower tertile $(n=374)$ & 13 & 3.5 & $1.86-5.87$ \\
\hline Middle tertile $(n=662)$ & 41 & 6.2 & $4.48-8.31$ \\
\hline Upper tertile $(n=339)$ & 10 & 2.9 & $1.42-5.35$ \\
\hline \multicolumn{4}{|c|}{ Symptoms associated with fever $(n=64)$} \\
\hline Headache & 21 & 32.8 & \\
\hline Body ache & 10 & 15.6 & \\
\hline Nausea/vomiting & 1 & 1.5 & \\
\hline Abdominal pain & 7 & 10.9 & \\
\hline Diarrhoea & 6 & 9.4 & \\
\hline Running nose & 10 & 15.6 & \\
\hline Sore throat & 5 & 7.8 & \\
\hline Cough & 38 & 59.4 & \\
\hline Breathing difficulty & 6 & 9.4 & \\
\hline
\end{tabular}

However, none of these differences was statistically significant, with overlapping 95\% CI (Table 3).

Blood samples were collected from 1173 individuals in March and 1106 individuals in August to test at the point of survey for $P$. falciparum specific antigen; all were negative. The 2279 blood smears examined by microscopy several months after the survey were all negative for $P$. falciparum and P. vivax.

\section{Actions taken to treat the fever}

In March and August 48 cases of fever reported to have occurred over the previous 14 days had resolved by the day of the interview, and therefore could be used to define complete treatment actions. At least 1 reported action was taken to manage $31 / 48$ (64.6\%) of these fevers: the first action taken was predominantly reported to be prayers or supplications (35.4\% of respondents).

Only $37.5 \%(n=18)$ of fevers were managed at a formal health post or clinic at any time during the illness. Seven (38.9\%) visited an $\mathrm{HP}$ or $\mathrm{MCH} /$ OPD within 24 hours, 7 (38.9\%) within $24-<48$ hours and 3 (16.7\%) within $48-<72$ hours. Only 1 person visited an $\mathrm{HP}$ or $\mathrm{MCH} / \mathrm{OPD}$ more than 72 hours from the onset of fever. Most of those who visited a health facility were in the middle $(n=11,61.1 \%)$ and upper $(n=6,33.3 \%)$ wealth tertiles, most were men $(n=13,72.2 \%)$ and half were children below the age of 15 years $(n=9,50.0 \%)$. Medicines used to treat the febrile illnesses included antibiotics, antipyretics and vitamins. None reported the prescription or use of an antimalarial drug and none of the fevers was investigated by microscopy or rapid diagnostic tests

\section{Discussion}

Among the residents of 3 rural communities in Gebiley district, fever was a relatively rare condition when investigated in March and August of 2008. Across the 2 surveys, a total of 64 fevers were reported among 2306 person-fortnight observations, a projected estimated incidence of 0.72 fever events per person per year. We were surprised by this low period prevalence of a condition considerably more prevalent in other African settings when investigated using identical methodologies. Outside southern Africa, the predicted incidence of fever ranged from 3 to 13 attacks per child aged $<5$ years per year [9] compared to a projected incident fever rate of 0.69 among the children of this age range in the 3 villages in this study.

The word for fever, xumad (pronounced humad), is unambiguous in the local vernacular and unlikely to have been misinterpreted. Most fevers were associated with other symptoms, notably those indicative of upper respiratory tract and gastrointestinal infections. We did not investigate across the surveys the full range of morbid conditions affecting these communities as the entry point for this investigation was fever. It is notable however that none of the people examined harboured malaria infection in their peripheral blood. Fever prevalence was, therefore, independent of malaria and likely to be a consequence of the acquisition of other circulating bacterial and viral infections. What this study may suggest is that the overall prevalence of fever may well scale with the likelihood and intensity of malaria transmission in a given setting and this simple proxy of "malaria risk" merits further investigation.

There is no doubt that these communities are impoverished with no electricity, ready access to water or material goods. Just over a third of those having febrile events visited a health post or health centre. When asked about the possible reasons why treatment was not sought for their fevers outside the home, respondents said that they thought the fever was mild and that it would resolve spontaneously and if they did wish to seek treatment, it would cost too much 
to travel, obtain a consultation and pay for the medicines. This does have implications for possible future major malaria outbreaks in this area.

Transmission of both P. falciparum and $P$. vivax is possible in all 3 villages following the identification of Anopheles arabiensis larvae in breeding sites surrounding the villages in July 2008 [F.S. Deria, 2008, Entomological survey in three villages of Gebiley district, Somaliland, unpublished report] and the description of infection among human hosts in neighbouring villages [4]. The threat of an outbreak of malaria is always present in these communities, particularly after heavy rains or the importation of infection by nomadic pastoralists. Should an outbreak of fever/malaria occur in these communities, it is unlikely it would be detected promptly given the incipient delays in fever treatment and the fact that none of the fevers were parasitologically investigated by health care personnel. It would therefore be advisable to improve community awareness of the potential seriousness of fevers and the need for their thorough investigation. Overcoming physical barriers of access to diagnostic services, costs of diagnosis and the perceived benign nature of all febrile events should be issues that require addressing as part of improved malaria surveillance for outbreak detection in this area of Somalia.

\section{Acknowledgements}

The authors wish to thank Abdikarim Yusuf, RBM/WHO Somalia Country Office for training and supervision of laboratory technicians, Fahim Yusuf, RBM/WHO Somalia Country Office and Ahmed Noor, Director of Gebiley District Hospital for facilitating the training of surveyors and supervision of the field work. The administrative support for this study was ably provided by Tanya Shewshuk, UNICEF-Somalia, WHO, UNICEF country offices and KEMRI, notably Wafaa Said, Ahmed Mohamed Jama and Lydiah Mwangi. We acknowledge the technical support for microscopy provided by Moses Mosobo and Ken Awuondo of the KEMRI-Wellcome Trust programme at Kilifi, Kenya.

Finally we wish to thank the clan elders, heads of homesteads and community members who participated in this survey and to whom the investigators are deeply indebted.

AMN and RWS are supported by the Wellcome Trust UK (081829 and 079081 awards respectively) and acknowledge the support of the Director, KEMRI.

Funds for the survey were provided by the GFATM to UNICEFSomalia as the sub-recipient (ref: $\mathrm{YH} / 101 / 04 / 08$ ).

\section{References}

1. Sheik-Mohammed A, Velema JP. Where health care has no access: the nomadic populations of sub-Saharan Africa. Tropical medicine \& international health, 1999; 4:695-707.

2. Capobianco E. Somalia malaria strategy 2005-2010. New York, United Nations Children's Fund, 2005.

3. Wilson DB. Malaria in British Somaliland. East African medical journal, 1949, 26:283-91.

4. Noor AM et al. Spatial prediction of Plasmodium falciparum prevalence in Somalia. Malaria journal, 2008, 7:159.

5. Glasgow JP, Maclnnes DG. Anopheles of British Somaliland. East African medical journal, 1943; 20:176-9.
6. Maffi M. Contributo alla conoscenza della fauna anofelinica della Somalia [Contribution to the knowledge of the anopheline fauna of Somalia]. Rivista di malariologia, 1958, 37:73-5.

7. Google Earth [website]. Seattle, United States of America, Google, 2009 (http://earth.google.com/, accessed 10 December 2009).

8. Basic laboratory methods in medical parasitology. Geneva, World Health Organization, 1991.

9. Snow RW, Eckert E, Teklehaimanot A. Estimating the needs for artesunate-based combination therapy for malaria casemanagement in Africa. Trends in parasitology, 2003, 19:363-9. 